\title{
What do foreign neighbors say about the mental lexicon?*
}

MICHAEL S. VITEVITCH

Department of Psychology University, of Kansas

(Received: August 17, 2010; final revision received: February 25, 2011; accepted: March 3, 2011; First published online 7 April 2011)

A corpus analysis of phonological word-forms shows that English words have few phonological neighbors that are Spanish words. Concomitantly, Spanish words have few phonological neighbors that are English words. These observations appear to undermine certain accounts of bilingual language processing, and have significant implications for the processing and representation of word-forms in bilinguals.

Keywords: phonological neighbor, Spanish, English, corpus analysis

"It is uncontroversial that both languages of a bilingual are jointly activated during all linguistic processing, even in strongly monolingual contexts in which the nontarget language would be considered inappropriate" (Bialystok, 2010, p. 562). Indeed, many studies have found evidence of cross-language influences on processing, such as the activation or the inhibition of phonologically related word-forms (e.g., De Groot, Delmaar \& Lupker, 2000; Duyck, 2005; Lemhöfer \& Dijkstra, 2004). Some studies have defined phonologically similar word-forms as being cognates (words in two languages with a common etymological origin resulting in similar phonological characteristics and the same meaning: map (English) and mapa (Spanish); e.g., Costa, Caramazza \& SebastiánGallés, 2000), or homophonous in some way (e.g., homographs, homophones, pseudo-homophones; two words that look or sound the same but have different meanings: see/sea (English) and si (Spanish)).

Rather than use words like cognates or homophonous word-forms (which are relatively unique in the languages of the world and therefore limit the generalizability of studies that employ them), the present corpus analysis measured phonological neighborhood density in an English and a Spanish lexicon to assess the extent to which words in one language are phonologically similar to words in the other language. PhONOLOGICAL NEIGHBorhood DENSITY refers to the number of words that sound similar to a given word, and has been shown to influence a variety of language-related processes including word learning

\footnotetext{
* This research was supported in part by a grant from the National Institutes of Health to the University of Kansas through the Schiefelbusch Institute for Life Span Studies: National Institute on Deafness and Other Communication Disorders R01 DC 006472. I would like to thank Melissa Stamer for helpful comments and suggestions on earlier drafts, and Holger Mitterer for suggesting the analysis that took vowel assimilation into account.
}

(Storkel, Armbruster \& Hogan, 2006), word recognition in English (Luce \& Pisoni, 1998), word recognition in Spanish (Vitevitch \& Rodríguez, 2005), word production in English (Vitevitch, 2002), word production in Spanish (Vitevitch \& Stamer, 2006, 2009), and serial-recall of words (Roodenrys et al., 2002).

If many word-forms in one language are phonologically similar to many word-forms in another language, then it is reasonable to assume that there might be a large amount of cross-language activation or inhibition among word-forms. Large amounts of activation or inhibition from another language might indeed present the lexical processing system of the bilingual with a difficult computational problem, one which requires additional mechanisms and processes to retrieve the correct wordform from the "correct" language (e.g., in production: Green (1998), in perception: Dijkstra \& van Heuven (2002); among others).

Conversely, if few word-forms in one language are phonologically similar to word-forms in another language, then the lexical processing system in the bilingual individual might not be as challenged as previous studies imply. This is not to say that cross-language influences on processing do not exist; a large number of studies have demonstrated such influences with a variety of methodologies and languages. Rather, such a finding might undermine the need for some of the cognitive mechanisms (e.g., Bialystok, 2010) or representational schemes (e.g., Green, 1998) that have been proposed in the bilingual individual, compelling researchers to consider and explore alternative explanations for the observations made to date (e.g., Meara, 2006).

\section{Methods}

The English corpus used in this present analysis contained the 19,340 words from the Merriam-Webster Pocket

Address for correspondence:

Michael S. Vitevitch, Spoken Language Laboratory, Department of Psychology, 1415 Jayhawk Blvd., University of Kansas, Lawrence, KS 66045, USA

mvitevit@ku.edu 
Dictionary (1964; see Nusbaum, Pisoni \& Davis, 1984; Storkel \& Hoover, 2010; Vitevitch \& Luce, 2004, for additional information about this corpus), and the Spanish corpus consisted of a randomly sampled set of 19,340 words from the LEXESP database (SebastiánGallés et al., 2000). Both lexicons have been used in numerous psycholinguistic studies and corpus analyses (e.g., Arbesman, Strogatz \& Vitevitch, 2010; Sandoval et al., 2010). Using equal numbers of words in the two lexica facilitated comparison within and between the two languages. Importantly, the words in each corpus occurred in their respective languages with approximately equal token frequency (Spanish mean frequency $=$ 45.92 occurrences per million $(s d=1779.14)$; English mean frequency $=40.76$ occurrences per million $(s d=$ $724.160) ; t(38678)=.37, p=.71)$ further attesting to the comparability of the two corpora.

Words were considered phonological neighbors of each other if they differed by the addition, deletion, or substitution of a single phoneme (Greenberg \& Jenkins, 1967; Landauer \& Streeter, 1973; Luce \& Pisoni, 1998; see also Levenshtein, 1966; Vitevitch, 2008). For example, the English words key and bee are neighbors because they differ by the substitution of one phoneme, $/ \mathrm{b} /$ for $/ \mathrm{k} /$. The English word key and the Spanish word si are also neighbors because they differ by the substitution of one phoneme, $/ \mathrm{s} /$ for $/ \mathrm{k} /$. This method of operationally defining phonological similarity has psychological validity (e.g., Cutler et al., 2000; Luce \& Large, 2001), and has been shown to produce results qualitatively similar to other operational definitions of phonological similarity (Luce \& Pisoni, 1998).

The same phonological transcription was used to represent phonemes that were common to both languages. Ignoring the well-known phonetic differences in the way certain phonemes are realized in each language (e.g., differences in voice-onset time) actually biases the present analysis to identify more words as phonological neighbors than a real speaker of the two languages might identify (see Ju \& Luce, 2004, for evidence that listeners use these fine-grained phonetic differences to activate word-forms only in the appropriate language during word recognition). As will be seen below, however, this bias to identify more words as phonological neighbors than a real speaker of the two languages might identify makes the results of the present analysis perhaps even more surprising.

\section{Results}

\section{Phonological neighbors within each language}

Looking at the phonological neighbors WITHIN each language, $47 \%$ of the words in the English lexicon had one or more English words as a phonological neighbor, whereas $27 \%$ of the words in the Spanish lexicon had one or more Spanish words as a phonological neighbor. ${ }^{1}$ The proportion of words with phonological neighbors in this sample of Spanish words is comparable to the value obtained by Arbesman et al. (2010) for the full LEXESP lexicon, suggesting that the random sample that was selected for the present analysis is representative of the larger population of Spanish words.

\section{Phonological neighbors between each language}

Looking at the phonological neighbors BETWEEN the two languages, only $4 \%$ of the 19,340 English words had one or more Spanish words as phonological neighbors (about 774 words). For the English words with Spanish neighbors, the increase in the size of the phonological neighborhood was only 1.55 neighbors (mean value). ${ }^{2}$

In the case of Spanish, only $2 \%$ of the 19,340 Spanish words had one or more English words as phonological neighbors (about 387 words). For the Spanish words with English neighbors, the increase in the size of the phonological neighborhood was 3.58 neighbors (mean value).

\section{The proportion of foreign and domestic neighbors}

Another way to look at phonological neighbors BETWEEN the two languages is to consider the total number of neighbors that each word has (both "foreign" and "domestic" neighbors) and assess the proportion of

1 The smaller proportion of Spanish words with phonological neighbors compared to the proportion of English words with phonological neighbors may be related to the fact that longer words tend to have fewer neighbors than shorter words (Vitevitch \& Rodríguez, 2005; Vitevitch, Stamer \& Sereno, 2008). Given that Spanish words tend to be longer than English words, it is perhaps not surprising that fewer Spanish words have phonological neighbors than English words. Spanish words being longer than English words is true for this sample of words (Spanish mean $=8.97$ phonemes per word, $s d=2.50$; English mean $=6.35$ phonemes per word, $s d=2.32 ; t(38678)=$ $106.77, p<.0001$ ), as well as the 520 pictures in Bates et al. (2003), where the Spanish words used to name the pictures had more syllables and more characters than the English words used to name the same pictures (i.e., the same concept): Spanish mean $=2.78$ syllables per word, $s d=.95 ;$ English mean $=1.75$ syllable per word, $s d=.84$; $t(1038)=18.55, p<.0001 ;$ Spanish mean $=6.48$ characters per word, $s d=2.14$; English mean $=4.95$ characters per word, $s d=2.22$; $t(1038)=4.30, p<.0001$, further suggesting that this is a general characteristic of the two languages, regardless of how word length is measured.

2 To give this observation some context, consider that English-speaking children have 1.43 neighbors per word at 16-months of age (based on the normative data from the MacArthur Communicative Development Inventory; Dale \& Fenson, 1996), and English-speaking adults have 6.89 neighbors per word (based on the present lexicon; N.B., these means do not include words that have 0 neighbors). In other words, English speakers acquire more phonological neighbors from learning English words throughout their lifetime than from learning another language. 


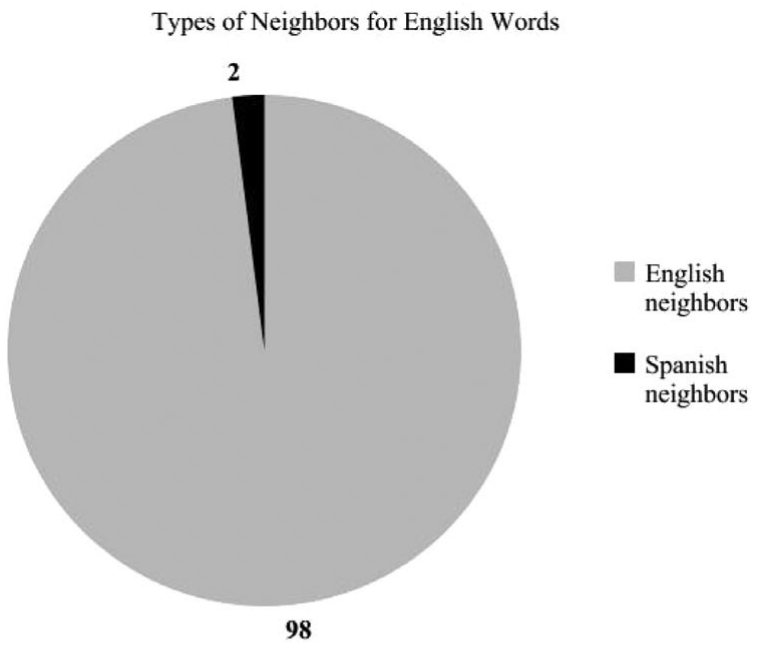

Types of Neighbors for Spanish Words

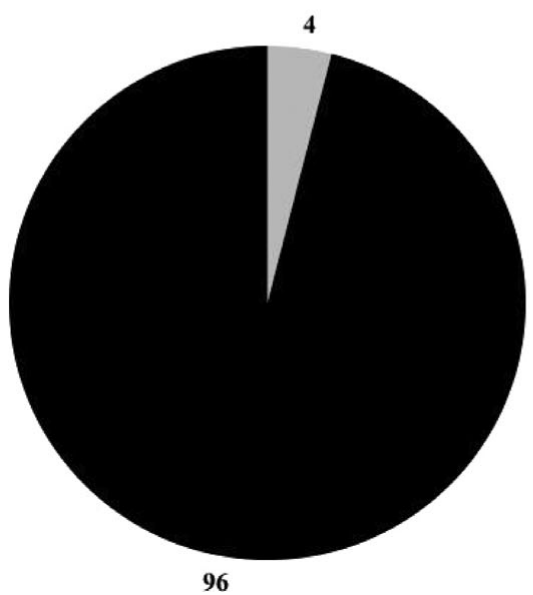

English neighbors

Spanish neighbors

Figure 1. The top panel shows, for English words, the percentage of neighbors that are English words and the percentage of neighbors that are Spanish words. The bottom panel shows, for Spanish words, the percentage of neighbors that are English words and the percentage of neighbors that are Spanish words.

neighbors from each language; see Figure 1 . When we examine the English words (the top panel of Figure 1), we find that 9,120 words had a neighbor of some sort, either "foreign" or "domestic" (note that a word must have at least one neighbor in this analysis, because division by 0 is undefined). For those 9,120 words with one or more neighbors, on average $98 \%$ of the words in the neighborhood of each word were English words, and only $2 \%$ of the words in the neighborhood were Spanish words.

For the Spanish words (the bottom panel of Figure 1), 5,197 words had at least one neighbor of some sort. For those 5,197 words with at least one neighbor, on average $96 \%$ of the words in the neighborhood of each word contained Spanish words, and only $4 \%$ of the words in the neighborhood of each word contained English words. These results further suggest that the number of words in one language that are phonologically similar to a word in another language is quite small.

\section{Replication with another corpus of Spanish words}

To verify that these observations were not spurious results due to the specific words in this sample of Spanish words or to the source of Spanish words that was used, these analyses were repeated with another Spanish lexicon (a random sample of 19,340 words from the 86,061 Spanish words obtained from ftp.ox.ac.uk $\backslash$ pub $\backslash$ wordlists $\backslash$ ), and the results were comparable. In this analysis, $32 \%$ of the words in the Spanish lexicon had one or more Spanish words as a phonological neighbor. Again, however, the proportion of neighbors from the other language was quite small: only $5.8 \%$ of the English words had one or more Spanish words as phonological neighbors, and only $2.5 \%$ of the Spanish words had one or more English words as phonological neighbors.

In addition, 6,179 Spanish words had at least one neighbor of some sort. For those 6,179 words with at least one neighbor, on average $95 \%$ of the words in the neighborhood of each word contained Spanish words, and only $5 \%$ of the words in the neighborhood of each word contained English words. These results obtained from a different database of Spanish words replicate the finding that there are few word-forms in one language that are phonologically similar to word-forms in another language.

\section{Replication taking perceptual assimilation into account}

The analyses performed thus far, however, assume 'perfect' perception of the sounds that comprise the English and Spanish words. It is well known that phonemic contrasts that exist in a second language are difficult to perceive if they do not exist in the native language. A classic example is the difficulty that native speakers of Japanese have in distinguishing the $/ \mathrm{r} /-/ 1 /$ contrast in English, because no such contrast exists in Japanese (e.g., MacKain, Best \& Strange, 1981). Similar difficulties are faced by native speakers of Spanish, a language with five vowels (/a e i o u/), when learning English, a language with about 20 vowels including diphthongs (e.g., / a $\rho$ e $\varepsilon$ I i v u o $æ \Lambda /$ ). To examine the impact that perceptual assimilation of English vowels onto Spanish vowel categories might have on phonological similarity, the same analyses were performed with the vowels in the English words replaced by the Spanish vowels they are most often perceived as (from García Lecumberri \& Cenoz Iragui, 1997, /i/ remained /i/; /e/ and /I/ became /e/; /æ $\Lambda$ a $\varepsilon /$ became /a/; $/ \mathrm{o} \cup \mathrm{o} / \mathrm{became} / \mathrm{o} / ; / \mathrm{u} / \mathrm{remained} / \mathrm{u} /$ ).

The number of English words (with Spanish vowels) that had one or more Spanish words as neighbors increased 
from $4 \%$ in the initial corpus (and 5.8\% in the replication with a different Spanish corpus) to $12.8 \%$. Note, however, that the proportion of English words (with Spanish vowels) with one or more Spanish neighbors is still significantly less than the proportion of Spanish words with one or more Spanish words as neighbors $(12.8 \%$ versus $\left.27 \% ; \chi^{2}(d f=1)=5.07, p<.05\right)$, again suggesting that there are more phonologically similar words within a language than between languages.

\section{Discussion}

The results of the present corpus analysis show, in several ways, that words in a foreign language do not "invade" the lexical neighborhoods of another language. That is, for the two languages examined here, there are few words in one language that are phonologically similar to words in the other language. This simple observation raises a number of important and fundamental questions about lexical retrieval and language processing in the bilingual.

First, the minimal amount of phonological overlap between the two languages essentially creates two separateor perhaps, easily separable - lexica. (Note that other lowlevel phonological information might further contribute to the separation of languages; see e.g., Ju \& Luce, 2004.) The DE FACTO separation between languages based on their phonological characteristics raises a question about the need for explicit representational schemes, such as language tags (Green, 1998) or language nodes (Dijkstra \& van Heuven, 1998), or other cognitive mechanisms (e.g., Bialystok, 2010) designed to keep the word-forms of one language separate from the wordforms of another language. If one considers the small number of words that might benefit from such measures, these approaches to language processing seem cognitively and computationally expensive (and seem increasingly expensive for the individual who knows a third, or fourth, etc. language).

If we consider the possibility that there is no cognitive mechanism or process that keeps the two languages separate in the lexicon of the bilingual, what could keep the two languages separate? There are, of course, a variety of phonological attributes that are used to characterize the languages of the world (e.g., phoneme inventory, phonotactic constraints, typical word-length, canonical syllable structure, etc.). The way in which these phonological characteristics uniquely combine in each language might be sufficient to keep the word-forms of each language essentially separate from each other without requiring an additional or explicit partitioning mechanism or process in the lexicon. Although explicit partitioning mechanisms and processes may appear to be superfluous in the mental lexicon, the possibility remains that such mechanisms or representational schemes might be useful at other levels of language processing (e.g., syntax, semantics, etc.) or for certain language processes (e.g., word learning).

It must be acknowledged that the methodology employed in the present study - corpus analysis limits what can be said directly about lexical processing. Even though there appear to be very few words in one language that are similar to words in another language, a single word from one language may be all that is needed to significantly affect the speed and accuracy with which lexical processing occurs in the other language. Indeed cross-language influences on processing, such as the activation or the inhibition of related word-forms, have been demonstrated (e.g., in production: Marian \& Blumenfeld, 2006). Other evidence, however, suggests that word recognition in a second language is primarily determined by within-language rather than cross-language factors (e.g. Lemhöfer et al., 2008). Thus, the processes described in current models of spoken-word recognition might be sufficient to retrieve the correct word-form from the "correct" language; no additional processing mechanisms may be required.

In all current models of spoken-word recognition (cohort theory: Gaskell \& Marslen-Wilson, 1997; TRACE: McClelland \& Elman, 1986; Shortlist: Norris, 1994; Neighborhood Activation Model: Luce \& Pisoni, 1998), several phonologically similar word-forms compete with each other during the process of spokenword recognition. It is reasonable to postulate that the same mechanism used to deal with the competition that exists among phonologically similar words within a given language is sufficient to deal with the additional competition that might arise from phonologically similar words in another language. With a relatively efficient mechanism already in place to deal with the competition among phonologically similar words within a given language, there appears to be no need to supplement that process with an additional mechanism to deal with the small number of competitors that might cross the "lexical boarders" from another language. ${ }^{3}$

Although the observations made on the basis of the present corpus analysis are small in number, the implications of these observations are far-reaching, and may compel some researchers of bilingual (and monolingual) language processing to explore alternative accounts of lexical retrieval (e.g., Meara, 2006).

\footnotetext{
3 Recall that spoken English words with sparse neighborhoods are recognized more quickly than English words with dense neighborhoods (Luce \& Pisoni, 1998), whereas spoken Spanish words with dense neighborhoods are recognized more quickly than Spanish words with sparse neighborhoods (Vitevitch \& Rodríguez, 2005). Future research is needed to understand how a "competitor" in one language might "facilitate" processing in another language (and vice versa), and to determine if any of the current models of (monolingual) spoken word recognition are capable of exhibiting both competition and facilitation amongt phonological neighbors.
} 
Furthermore, the observations made in the present corpus analysis raise a number of additional questions for future research. Perhaps the small amount of phonological overlap observed in the present analysis was due to the languages that were examined, English and Spanish. Although English and Spanish are both Indo-European languages, English is from the Germanic branch, whereas Spanish comes from the Romance branch. Perhaps if two Romance or two Germanic languages were considered, a larger amount of phonological overlap might be observed. ${ }^{4}$ This leads to an additional testable hypothesis: the amount of cross-language influence observed in lexical processing might be related to the amount of phonological overlap that exists between the two languages (Brauer (1998) and Dijkstra et al. (2010) indeed found processing differences as a function of language similarity, whereas Costa, Santesteban \& Ivanova (2006) failed to find processing differences as a function of language similarity). Similarly, the cognitive advantages often associated with being bilingual (e.g., Bialystok, 2010) might be dependent on the two languages that one knows: an individual who knows two languages with a large amount of phonological overlap may possess a stronger executive control system than an individual who knows two languages with a small amount of phonological overlap.

The apparent asymmetry in the extent to which words of one language "invade" the lexical neighborhoods of the other language also warrants additional investigation: English words showed an increase in neighborhood size of only 1.55 Spanish neighbors, but Spanish words showed an increase in neighborhood size of 3.58 English neighbors. This asymmetry suggests that something other than proficiency in the languages may affect crosslanguage influences in lexical processing (to the extent that they exist): in concurrent bilinguals with equal levels of proficiency there may be a greater influence of English words on Spanish processing than of Spanish words on English processing.

On a methodological note, the corpus analysis employed in the present study might also prove to be a useful approach in other areas of language research. For example, historical or comparative linguists could use a technique similar to the one employed in the present study to measure the occurrence of phonological overlap between two languages to serve as a baseline for the rate of occurrence of cognates, etc., or to assess the likelihood that one language branched off from another language. Intriguing research questions and novel methodological approaches such as these might not have been posed in the absence of the present observations.

\footnotetext{
4 Indeed, the present metric offers a quantitative alternative to the nonmetric (and not uncontroversial) division of languages into "families", which is sometimes used as a proxy to assess language similarity.
}

\section{References}

Arbesman, S., Strogatz, S. H., \& Vitevitch, M. S. (2010). The structure of phonological networks across multiple languages. International Journal of Bifurcation and Chaos, 20, 679-685.

Bates, E., D'Amico, S., Jacobsen, T., Szekely, A., Andonova, E., Devescovi, A., Herron, D., Lu, C.-C., Pechmann, T., Pleh, C., Wicha, N., Federmeier, K., Gerdjikova, I., Gutierrez, G., Hung, D., Hsu, J., Iyer, G., Kohnert, K., Mehotcheva, T., Orozco-Figueroa, A., Tzeng, A., \& Tzeng, O. (2003). Timed picture naming in seven languages. Psychonomic Bulletin \& Review, 10, 344-380.

Bialystok, E. (2010). Bilingualism. Wiley Interdisciplinary Reviews: Cognitive Science, 1, 559-572.

Brauer, M. (1998). Stroop interference in bilinguals: The role of similarity between the two languages. In A. F. Healy \& L. E. Bourne, Jr. (eds.), Foreign language learning: Psycholinguistic studies on training and retention, pp. 317 337. Mahwah, NJ: Lawrence Erlbaum.

Costa, A., Caramazza, A., \& Sebastián-Gallés, N. (2000). The cognate facilitation effect: Implications for models of lexical access. Journal of Experimental Psychology: Learning, Memory, and Cognition, 26, 1283 1296.

Costa, A., Santesteban, M., \& Ivanova, I. (2006). How do highly proficient bilinguals control their lexicalization process? Inhibitory and language-specific selection mechanisms are both functional. Journal of Experimental Psychology: Learning, Memory and Cognition, 32, 1057-1074.

Cutler, A., Sebastián-Gallés, N., Soler-Vilageliu, O., \& van Ooijen, B. (2000). Constraints of vowels and consonants on lexical selection: Cross-linguistic comparisons. Memory \& Cognition, 28, 746-755.

Dale, P. S., \& Fenson, L. (1996). Lexical development norms for young children. Behavioral Research Methods, Instruments, \& Computers, 28, 125-127.

De Groot, A. M. B., Delmaar, P., \& Lupker, S. J. (2000). The processing of interlexical homographs in translation recognition and lexical decision: Support for non-selective access to the bilingual memory. The Quarterly Journal of Experimental Psychology, 2, 397-428.

Dijkstra, A. [F. J.], \& Van Heuven, W. J. B. (1998). The BIAmodel and bilingual word recognition. In J. Grainger \& A. M. Jacobs (eds), Localist connectionist approaches to human cognition, pp. 189-225. Mahwah, NJ: Lawrence Erlbaum.

Dijkstra, A. F. J., \& Van Heuven, W. J. B. (2002). The architecture of the bilingual word recognition system: From identification to decision. Bilingualism: Language and Cognition, 5, 175-197.

Dijkstra, T. [A. F. J.], Miwa, K., Brummelhuis, B., Sappelli, M., \& Baayen, H. (2010). How cross-language similarity and task demands affect cognate recognition. Journal of Memory \& Language, 62, 284-301.

Duyck, W. (2005). Translation and associative priming with cross-lingual pseudohomophones: Evidence for nonselective phonological activation in bilinguals. Journal of Experimental Psychology: Learning, Memory, and Cognition, 31, 6, 1340-1359. 
García Lecumberri, M. L., \& Cenoz Iragui, J. (1997). L2 perception of English vowels: Testing the validity of Kuhl's prototypes. Revista Alicantina de Estudios Ingleses, 10, 55-68.

Gaskell, M. G., \& Marslen-Wilson, W. D. (1997). Integrating form and meaning: A distributed model of speech perception. Language and Cognitive Processes, 12, 613656.

Green, D. W. (1998). Mental control of the bilingual lexicosemantic system. Bilingualism: Language \& Cognition, 1, 67-81.

Greenberg, J. H., \& Jenkins, J. J. (1967). Studies in the psychological correlates of the sound system of American English. In L. A. Jakobovits \& M. S. Miron (eds.), Readings in the psychology of language, pp. 186-200. Englewood Cliffs, NJ: Prentice-Hall.

Ju, M., \& Luce, P. A. (2004). Falling on sensitive ears: Constraints on bilingual lexical activation. Psychological Science, 15, 314-318.

Landauer, T. K., \& Streeter, L. A. (1973). Structural differences between common and rare words: Failure of equivalence assumptions for theories of word recognition. Journal of Verbal Learning \& Verbal Behavior, 12, 119131.

Lemhöfer, K., \& Dijkstra, T. [A. F. J.] (2004). Recognizing cognates and interlingual homographs: Effects of code similarity in language-specific and generalized lexical decision. Memory \& Cognition, 32, 533-550.

Lemhöfer, K., Dijkstra, T. [A. F. J.], Schriefers, H., Baayen, R. H., Grainger, J., \& Zwisterlood, P. (2008). Native language influences on word recognition in a second language: A megastudy. Journal of Experimental Psychology: Learning, Memory \& Cognition, 34, 12-31.

Levenshtein, V. I. (1966). Binary codes capable of correcting deletions, insertions, and reversals. Soviet Physics Doklady, 10, 707-710.

Luce, P. A., \& Large, N. R. (2001). Phonotactics, density and entropy in spoken word recognition. Language and Cognitive Processes, 16, 565-581.

Luce, P. A., \& Pisoni, D. B. (1998). Recognizing spoken words: The neighborhood activation model. Ear and Hearing, 19, $1-36$.

MacKain, K. W., Best, C. T., \& Strange, W. (1981). Categorical perception of English / $\mathrm{r} /$ and $/ \mathrm{l} /$ by Japanese bilinguals. Applied Psycholinguistics, 2, 369-390.

Marian, V., \& Blumenfeld, H. (2006). Phonological neighborhood density guides lexical access in native and non-native language production. Journal of Social and Ecological Boundaries, 2, 3-35.

McClelland, J. L., \& Elman, J. L. (1986). The TRACE model of speech perception. Cognitive Psychology, 18, 1-86.

Meara, P. (2006). Emergent properties of multilingual lexicons. Applied Linguistics, 27, 620-644.
Norris, D. (1994). Shortlist: A connectionist model of continuous speech recognition. Cognition, 52, 189-234.

Nusbaum, H. C., Pisoni, D. B., \& Davis, C. K. (1984). Sizing up the Hoosier mental lexicon: Measuring the familiarity of 20,000 words (Research on Speech Perception, Progress Report No. 10). Bloomington, IN: Indiana University, Psychology Department, Speech Research Laboratory.

Roodenrys, S., Hulme, C., Lethbridge, A., Hinton, M., \& Nimmo, L. M. (2002). Word-frequency and phonologicalneighborhood effects on verbal short-term memory. Journal of Experimental Psychology: Learning, Memory, and Cognition, 28, 1019-1034.

Sandoval, T. C., Gollan, T. H., Ferreira, V. S., \& Salmon, D. P. (2010). What causes the bilingual disadvantage in verbal fluency? The dual-task analogy. Bilingualism: Language and Cognition, 13, 231-252.

Sebastián-Gallés, N., Marti-Antonin, M. A., Carreiras-Valina, M. F., \& Cuetos-Vega, F. (2000). Lexesp. Lexico informatizado del espanol. In Edicions de la Universitat de Barcelona. [CD-ROM]

Storkel, H. L., Armbruster, J., \& Hogan, T. P. (2006). Differentiating phonotactic probability and neighborhood density in adult word learning. Journal of Speech, Language, and Hearing Research, 49, 1175-1192.

Storkel, H. L., \& Hoover, J. R. (2010). An on-line calculator to compute phonotactic probability and neighborhood density based on child corpora of spoken American English. Behavior Research Methods, 42, 497-506.

Vitevitch, M. S. (2002). The influence of phonological similarity neighborhoods on speech production. Journal of Experimental Psychology: Learning, Memory and Cognition, 28, 735-747.

Vitevitch, M. S. (2008). What can graph theory tell us about word learning and lexical retrieval? Journal of Speech Language Hearing Research, 51, 408-422.

Vitevitch, M. S., \& Luce, P. A. (2004). A web-based interface to calculate phonotactic probability for words and nonwords in English. Behavior Research Methods, Instruments, and Computers, 36, 481-487.

Vitevitch, M. S., \& Rodríguez, E. (2005). Neighborhood density effects in spoken word recognition in Spanish. Journal of Multilingual Communication Disorders, 3, 64-73.

Vitevitch, M. S., \& Stamer, M. K. (2006). The curious case of competition in Spanish speech production. Language \& Cognitive Processes, 21, 760-770.

Vitevitch, M. S., \& Stamer, M. K. (2009). The influence of neighborhood density (and neighborhood frequency) in Spanish speech production: A follow-up report (University of Kansas). Spoken Language Laboratory Technical Report, 1, 1-6.

Vitevitch, M. S., Stamer, M. K., \& Sereno, J. A. (2008) Word length and lexical competition: Longer is the same as shorter. Language \& Speech, 51, 361-383. 